\title{
Remembering old partnerships: Networking as new medical schools within BoLeSwa countries
}

\author{
L Badlangana, ${ }^{1} \mathrm{PhD} ; \mathrm{K}$ Matlhagela, ${ }^{1} \mathrm{PhD} ; \mathrm{N}$ Tlale $,{ }^{2} \mathrm{MB} \mathrm{ChB}, \mathrm{MMed}(\mathrm{O} \& \mathrm{G})$ \\ ${ }^{1}$ Department of Biomedical Sciences, Faculty of Medicine, University of Botswana, Gaborone, Botswana \\ ${ }^{2}$ Medical School of Lesotho, Ministry of Health, Maseru, Lesotho
}

Corresponding author: L Badlangana (ludo.badlangana@mopipi.ub.bw)

In southern Africa, former members of the Botswana-Lesotho-Swaziland (BoLeSwa) partnership, Botswana and Lesotho, have established their first and only publicly funded medical schools in their countries. Swaziland has a private medical school. The three countries have a long history of partnership through the University of Botswana, Lesotho and Swaziland (UBLS) system - a derivative of BoLeSwa. Botswana and Lesotho are also members of a newly founded Consortium of New Southern African Medical Schools (CONSAMS). The UBLS was established in Lesotho in 1964 by a royal charter, two years before the three countries gained independence. It was founded to address manpower constraints in anticipation of their independence. The three countries had agreed to concentrate on different professional trainings, as follows: Botswana in engineering, Swaziland in agriculture, and Lesotho in medicine. CONSAMS was established as a unique collaborative approach involving south-south networks, which included south-north partnerships. This created an opportunity to strengthen medical education in the region. The BoLeSwa partnership is further strengthened by participation in CONSAMS by two of the five founding members. Other members include Mozambique, Namibia and Zambia. A sharing of resources through regional and international partnerships has been established. The sub-Saharan African Medical School Study has examined the challenges, innovations, and emerging trends in medical education in the region and has made recommendations on how to better share resources. CONSAMS is one innovative way of addressing these issues. Partnerships between the BoLeSwa countries have been strengthened through CONSAMS. This has afforded the new medical schools sharing of their limited resources.

Afr J Health Professions Educ 2016;8(2):130-131. DOI:10.7196/AJHPE.2016.v8i2.525

Many African countries are involved in complex plans to improve medical education as part of health sector strengthening. Several governments in sub-Saharan Africa are investing heavily in human resources for health in response to this urgent need. ${ }^{[1]}$ The 2010 United Nations Report projects the establishment of numerous new medical schools in the sub-Saharan region by $2020 .{ }^{[1]}$ In 2007, Boulet et al. ${ }^{[2]}$ reported that 16 of 57 African nations did not have a medical school; many of the southern African countries were among these. In southern Africa, the Botswana and Lesotho governments have established their first medical schools in their countries. These countries and Swaziland have a long history of partnership through the University of Botswana, Lesotho and Swaziland (UBLS) system. This is a derivative of what was commonly known as the BoLeSwa partnership. Swaziland, however, has a newly founded private medical school. ${ }^{[3]}$

The UBLS was established in Lesotho in 1964 by a royal charter, two years before Botswana, Lesotho and Swaziland attained independence. ${ }^{[4,5]}$ It was founded to address manpower constraints in the face of the soon-to-be newly independent countries that needed to 'sustain [their] existence. ${ }^{[4,5]}$ The UBLS was based between the main campus in Lesotho and the evolving campuses in Botswana and Swaziland. The countries had agreed to concentrate on different professional trainings: Botswana in engineering, Swaziland in agriculture, and Lesotho in medicine. ${ }^{[4,5]}$

The three governments were not able to achieve their goal of establishing a medical school in Lesotho owing to the collapse of the UBLS. The three countries ultimately established their own separate universities.

\section{The University of Botswana School of Medicine}

Before the establishment of the University of Botswana School of Medicine (UBSOM), Botswana placed $>500$ students in $>15$ partner medical schools.
The training of students outside Botswana cost the government more than USD500 million in tuition and living expenses. Unfortunately, too few students return to Botswana upon completion of their training. Those who do return are not retained owing to their inadequate adaptation on the Botswana healthcare environment; this continued to put strain the system. This model of training medical doctors proved to be financially unsustainable. The number of Batswana doctors remains too low to meet the increasing population and demand for improved healthcare service delivery.

In 1995, the government commissioned a feasibility study to explore the notion of starting a medical school. This was followed in 1998 by a presidential directive to establish a medical school in phases. The first phase involved training selected students in Botswana for two years of a BSc degree before sending them to various partner medical schools in South Africa, Australia, Europe and the Caribbean. In August 2009, the UBSOM accepted its first medical students, who completed their training locally. This marked the final phase in the establishment of a medical school. The first cohort of Botswana-trained doctors graduated in October 2014 and the second in 2015.

\section{The Lesotho Medical School}

Several efforts were made since 1974 to establish a medical school in Lesotho. While preparing for this, Lesotho - as Botswana - trained its students in other countries and faced similar financial and human resource losses. The last effort was made in 2010. It was preceded by a positive feasibility study and a roadmap for the project. Because of the urgency of the project, the University of Zimbabwe assisted Lesotho by training three cohorts of students in biomedical sciences and preclinical work. The first cohort will complete their training in 2016, their degrees being awarded 


\section{Short research report}

by the University of Zimbabwe until the Lesotho Medical School (LMS) becomes fully operational.

A consortium of new medical schools, the Consortium of New Southern African Medical Schools (CONSAMS), ${ }^{[6,7]}$ has been formed and includes Botswana and Lesotho as founding members. This new partnership has resuscitated the old relationship of BoLeSwa between the two countries. It was established as a unique collaborative approach involving south-south networks, which include a north-south partnership. ${ }^{[7]}$ The network creates a unique opportunity to strengthen medical education in the region. ${ }^{[7]}$ Southern Africa has an extremely low physician to high population ratio, as is the case throughout sub-Saharan Africa. A number of reports and recommendations have been published advising policy makers and medical schools on medical education in the region, such as the sub-Saharan African Medical School Study (SAMSS). SAMSS examined the challenges and emerging trends in medical education in the region. ${ }^{[8]}$ In southern Africa, there is an effort by CONSAMS to address such challenges through the collaboration of new medical schools by sharing and exchanging resources via a well-planned platform.

\section{Hosting a CONSAMS meeting}

To capacitate the newly formed schools and to ensure that CONSAMS objectives are carried forward, partners communicate frequently to exchange ideas and report on the progress of key objectives by various means, including annual meetings. The CONSAMS schools alternately host the meetings, which assist the schools to attract key stakeholders to continue their support, as they share and appreciate the successes and challenges experienced by such schools. CONSAMS has held six meetings since its inception in 2010. The UBSOM hosted the third meeting in November 2012 and the LMS the fourth meeting in October 2013.
A number of funders have assisted in the running costs of CONSAMS and annual meetings and workshops that are regularly held. The partners include CONSAMS Medical Education Partnership Initiative (CONSAMSMEPI), the World Health Organization (WHO), and the Global Health through Education, Training and Service (GHETS). ${ }^{\left[{ }^{[9]}\right.}$

Our unique network forms a common medical training ground for our students. This has become invaluable to tackle our healthcare challenges. We have the flexibility to standardise our individual curricula according to our local contexts, e.g. we have facilitated faculty exchanges, external examiners, and student exchanges. The students are able to complete electives across varying environments without loss of time and finances.

\section{Conclusion}

CONSAMS has facilitated the revival of the next era in the BoLeSwa partnership, going beyond politics and investing in a healthier southern Africa.

\section{References}

1. Joint Learning Initiative. Human Resources for Health. Overcoming the Crisis. Cambridge, MA: Harvard, 2005 2. Boulet J, Bede C, Mckinley D, Norcini J. An overview of the world's medical schools. Med Teach 2007;29(1):20-26. DOI:10.1080/01421590601131823

. Magadza M. Swaziland: First school of medicine to be built. University World News, 3 July 2011. http://www. universityworldnews.com/article.php?story=20110701161600103 (accessed 5 July 2016).

4. Mokopakgosi BT. Why the University of Botswana, Lesotho and Swaziland failed: Lessons from the brief history of a region university in southern Africa. J Southern African Studies 2013;39(2):465-480. DOI:10.1080/03057070.2013.796737

5. Vernon-Jackson $\mathrm{HOH}$. Creating a new university campus: The University of Botswana, Lesotho and Swaziland. McGill J Educ 1973;8(2):198-207.

6. Magadza M. AFRICA: New medical schools seek strength in numbers. University World News, 20 November 2011. http://www.universityworldnews.com/article.php?story=20111118205356486 (accessed 5 July 2016).

7. Eichbaum Q, Nyarango P, Bowa K, et al. Global networks, alliances and consortia in global health education Eichbaum Q, Nyarango P, Bowa K, et al. Global networks, alliances and consortia in global health education
- the case for south-to-south partnerships. J Acquir Immune Defic Syndr 2012;61(3):263-264. DOI:10.1097/ the case for south-to-so

8. Mullan F, Frehywot S, Chen C, et al. The sub-Saharan African Medical School Study (SAMSS): Data, observation, and opportunity, 2010. https://smhs.gwu.edu/medicine/sites/medicine/files/125.pdf (accessed 5 July 2016).

9. Global Health through Education, Training and Service. Local knowledge, global health. www.ghets.org (accessed 5 July 2016). 